\title{
Entrevista com Renato Ortiz "Porque o mundo é comum, o diverso torna-se importante"
}

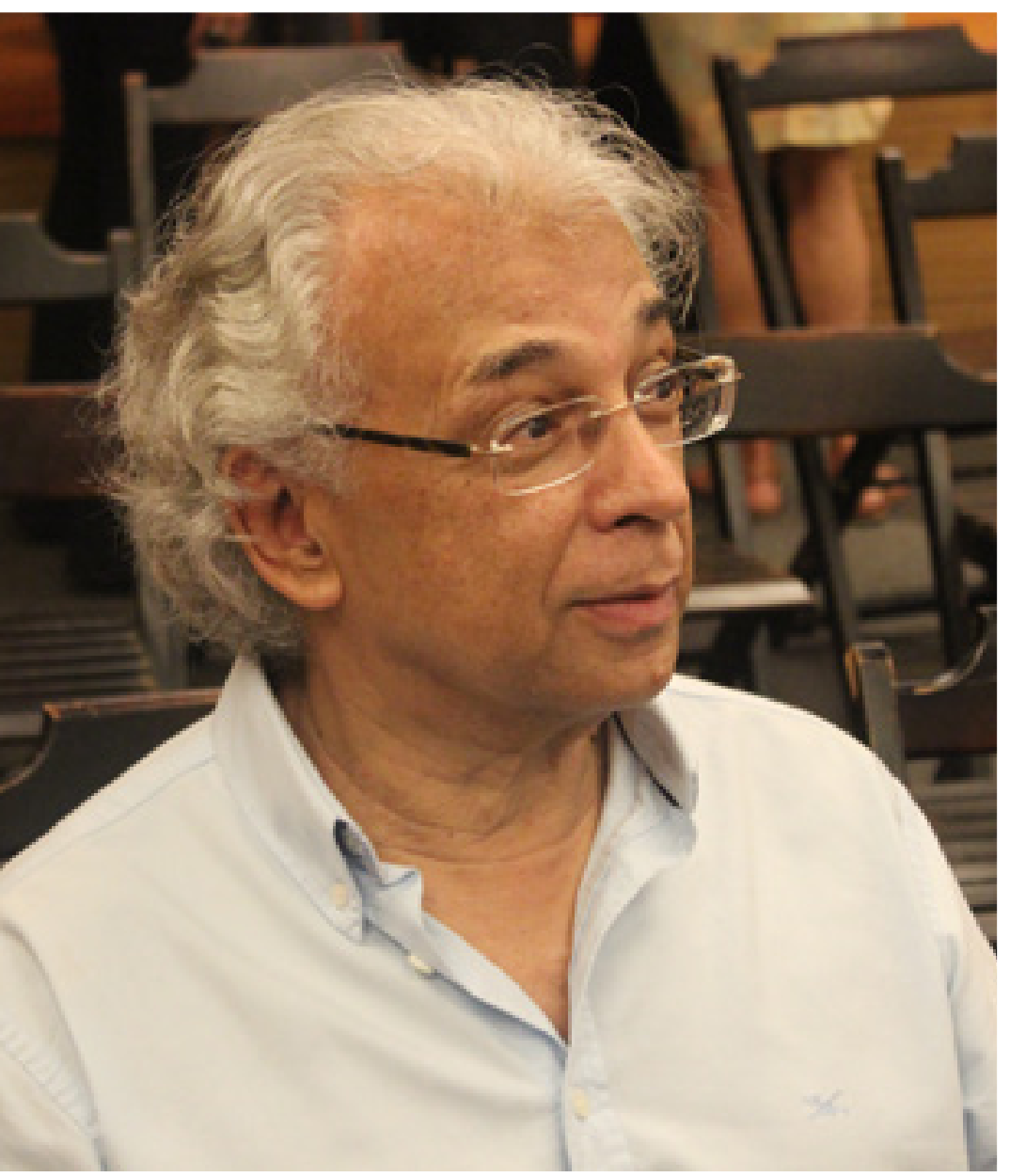

Boitempo), lançado em 2015, traça reflexões sobre as novas formas de encarar a problemática da diversidade, tema ao qual o autor também se dedica há alguns anos.

Nesta entrevista à Cadernos Cenpec, concedida em setembro de 2015, Renato problematiza as noções de universalismo e diversidade na contemporaneidade. Para ele, as duas noções devem ser compreendidas numa perspectiva relacional, não em oposição. "A diversidade ocorre no contexto da globalização", diz. Nele, a diversidade é ressignificada. No caso do Brasil, "até o século XX, nossa tradição era pensar a diversidade como uma síntese”, sendo o mestiço o exemplo dela. “Hoje, a diversidade é analítica; ela separa as diferenças, é democrática. Não é 
heterogênea como propõem os pós-modernos, nem homogênea como pensam os globalizados. Ela é o heterogêneo que se manifesta no homogêneo." Espera-se que as chaves interpretativas trazidas por ele possam contribuir para o entendimento dos modos pelos quais a diversidade é trabalhada no campo educacional.

Participaram da entrevista Antônio Augusto Gomes Batista, Hivy Damasio Araújo Mello e Joana Buarque de Gusmão, respectivamente coordenador e pesquisadoras da Coordenação de Desenvolvimento de Pesquisas do Cenpec. Edição de Silvana Salerno.

CADERNOS CENPEC - Gostaríamos que você falasse sobre sua trajetória profissional. Como chegou aos seus principais temas de pesquisa, especialmente à questão da diversidade?

RENATO ORTIZ - Os temas que trabalhei foram distintos, embora talvez seja possível dizer que existam algumas constâncias. Minha tese de doutorado em Paris, com Roger Bastide, foi sobre umbanda, chama-se "A morte branca do feiticeiro negro" . Assim, durante um tempo trabalhei a problemática da religião, que tinha algo de específico e se manteve ao longo das minhas preocupações. Eu me refiro ao tema da identidade, pois se tratava de definir a identidade de uma nova religião: como ela se legitimava, como elaborava suas dúvidas e certezas, convencia os fiéis e fundamentava sua autoridade. Estava claro, para mim, que essas questões não eram específicas do mundo religioso, uma vez que apareciam em diversas instâncias da esfera cultural. E fui, posteriormente, trabalhando isso de diversas maneiras: na identidade nacional, na questão das identidades particulares e no papel dos intelectuais na construção da identidade.

No final da década de 1970 e início dos anos 1980, dediquei-me ao estudo da identidade nacional e da modernidade. Escolhi esses temas porque estava insatisfeito com o que se dizia sobre o Brasil daquela época: era o Brasil da ditadura militar, um país moderno; e as pessoas falavam como se ele fosse totalmente subdesenvolvido, atrasado. Talvez o fato de eu ter ficado muitos anos na França tenha me dado um insight um pouco estrangeiro, eu percebia que o debate sobre a cultura brasileira e a identidade nacional, que era clássico entre nós e na América Latina, tinha de ser feito de uma outra forma.

Foi isso o que me levou a pensar a problemática da cultura brasileira, da

Publicada no Brasil em livro pela Editora Vozes e posteriormente pela Brasiliense. Cf. ORTIZ, Renato. A morte branca do feiticeiro negro: umbanda, integração de uma religião numa sociedade de classes. Petrópolis: Vozes, 1978. 
identidade nacional e da modernidade 2 . Só que, ao tratar isso, enveredei por um assunto que já conhecia no meu mestrado (feito na França, com Edgar Morin, do Centro de Cultura de Massa): a problemática da cultura de massa. Retornei a isso ao discutir a indústria cultural.

CADERNOS CENPEC - Como surgiu a sua reflexão sobre a globalização? E de que modo ela dialoga com a questão da diversidade?

RENATO ORTIZ - Nos Estados Unidos, fiz uma série de leituras quando estive no início dos anos 1980 na Columbia University (foi quando escrevi um longo texto sobre a Escola de Frankfurt e a questão da cultura); em seguida, a pesquisa empírica sobre telenovela abriu-me os olhos para essa produção industrial no interior de certas esferas da cultura; creio que isso conduziu-me ao tema da mundialização ${ }^{3}$. A partir daí, escrevi uma série de livros e artigos sobre a problemática 4 . Pude acompanhar o tema da diversidade ao longo desse trajeto. Num primeiro momento, aparecia como diversidade nacional, seguindo o debate dos autores clássicos dos quais me apropriei. Mas, ao longo das décadas de 1980 e 1990, a diversidade adquire uma nova configuração, que eu percebi, primeiro, por meio do debate sobre globalização, segundo, pela discussão sobre pós-modernidade e, terceiro, pela questão do póscolonialismo (esta nos anos 1990).

Também meus deslocamentos, encontros acadêmicos, congressos, conversas com colegas de várias partes do mundo ajudaram-me a entender que a temática da diversidade ia adquirindo uma conotação diferente. E é justamente nesse período que a Organização das Nações Unidas para a Educação, a Ciência e a Cultura (Unesco) publica sua carta de intenções a respeito da diversidade ${ }^{5}$. Digamos que por meio de minha trajetória e de meus estudos sobre a globalização consegui perceber que a temática adquiria um novo sentido.

Cf. Cultura brasileira e identidade nacional. São Paulo: Brasiliense, 1985.

Cf. A moderna tradição brasileira. Cultura brasileira e indústria cultura. São Paulo: Brasiliense, 1988.

Como, por exemplo, Mundialização e cultura. São Paulo: Brasiliense, 2007 [1994], e Mundialização: saberes e crenças. São Paulo: Brasiliense, 2006.

A Declaração universal sobre a diversidade cultural foi proclamada pela Unesco em 2002. Disponivel em: 〈http://unesdoc.unesco.org/images/0012/001271/127160por.pdf〉. Acesso em: 17 nov. 2015. 
CADERNOS CENPEC - Você acaba de lançar o livro Universalismo e diversidade: contradições da modernidade-mundo. Por que a questão da diversidade ganha importância no contexto contemporâneo?

RENATO ORTIZ - O tema da diversidade emerge porque o mundo se globalizou. Um dos capítulos do livro é sobre tradição e modernidade, em que procuro refletir sobre a questão do tempo e do espaço na situação de globalização. Creio que é possível dizer que a metáfora do espaço substituiu a do tempo - Foucault já tinha essa ideia, embora não a tenha elaborado tanto assim. Não é mais a questão do tempo que prevalece, se estamos "atrasados" ou "adiantados" em relação ao ideal eurocêntrico de civilização, termos que guiaram a discussão sobre a identidade nacional no Brasil e diversos outros países. Na situação de globalização, a metáfora do espaço se impõe: fazemos todos parte do mesmo planeta. Entretanto, somos diferentes. Existe assim uma dupla afirmação: a de comunalidade e de diferencialidade.

Eu havia "resolvido" isso de maneira conceitual quando cunhei a distinção entre globalização e mundialização; existe "um" mundo global na economia e na tecnologia, mas isso não ocorre na esfera cultural. Queria articular as mudanças culturais às transformações econômicas e tecnológicas, sem porém subsumi-las a elas. Existiria assim uma assimetria entre a esfera da cultura, na qual as diferenças se manifestam, e os níveis técnico e mercadológico. Nesse sentido, não creio que o tema da diversidade tenha se tornado relevante apenas porque a Unesco elaborou uma carta de princípios (claro, isso é importante). Ela é uma questão mais ampla, por isso digo no livro que a diversidade tornou-se um emblema do mundo contemporâneo. Emblema que constitui um oximoro. 0 exercício que fiz foi o de decodificar esse oximoro.

CADERNOS CENPEC - Ao analisar o contexto de globalização econômica e mundialização da cultura, você evita tratar algumas categorias de forma dicotômica ou excludente, contrapondo, por exemplo, a tradição à modernidade, o velho ao novo, o passado ao presente e, para entrar na questão da diversidade, o comum ao diverso, o universal ao particular. Quais os ganhos dessa opção analítica e quais as relações entre esses elementos/ categorias no contexto em que vivemos?

RENATO ORTIZ - Sempre tive uma grande desconfiança a respeito das dicotomias. Meus trabalhos sobre cultura brasileira já caminhavam nesta direção; no entendimento da identidade nacional procurava fugir da oposição imperialismo x nação, que me parecia reducionista. Claro que o importante era compreender as relações de poder, mas sem cair na visão dicotômica. 
Tenho feito isso em diversos textos. As categorias dicotômicas simplificam em demasia as coisas, têm uma aparência de verdade. No contexto atual temos: colonizador e colonizado, global e local. Fiz um esforço intelectual para evitar esse caminho. No caso da globalização, ainda nos anos 80 , havia autores que acreditavam na existência de um mercado global homogêneo. Nesse sentido, o mundo seria "plano", nivelado pelas exigências mercadológicas. Os pós-modernos afirmavam o contrário, tudo era diferença. Procurei me afastar dessas duas perspectivas ao dizer que o heterogêneo se manifesta no homogêneo. Os meus livros são isso. Nesse sentido, o tema da diversidade nunca me pareceu ser uma contradição em relação ao comum, ao “universal”.

Procurei assim escapar da oposição entre local e global, nacional e global, diverso e uno, heterogêneo e homogêneo. A língua é um bom exemplo disso. 0 surgimento do inglês como língua da modernidade-mundo não se reduz a uma questão colonial ou de imperialismo, tampouco ele implica o desaparecimento dos idiomas nacionais. 0 inglês é a língua hegemônica porque se desterritorializou no mercado de bens linguísticos; consolida-se, dessa forma, uma nova hierarquia na qual ele se torna o idioma central. Importa entender como este novo quadro linguístico configura a subalternidade dos outros idiomas ${ }^{6}$. Não se trata, portanto, de uma homogeneização, mas de uma diversificação hierarquizada na qual as relações de poder são evidentemente assimétricas.

CADERNOS CENPEC - Não é que o global "acabe” com o local, ele tensiona o local.

RENATO ORTIZ - Essa é a questão. Há tempos, quando dava uma conferência sobre a problemática da mundialização da cultura, uma jovem professora de uma universidade federal do Brasil central aproximou-se após o debate e me disse: "Renato, os índios lá da região não querem mais estudar português, querem estudar inglês. Eu acho isso um absurdo!" Eu disse a ela: "Você perguntou por que eles querem estudar inglês?" E ela respondeu: “Sim”. "Qual é o motivo?”, perguntei. “Eles disseram que querem negociar diretamente com as entidades internacionais sem passar pelas ONGs." Eu respondi: "Esses índios são muito inteligentes". Ou seja, o local deve ser situado num contexto mais amplo. Isso vale para a língua e para uma série de outras coisas.

Cf. ORTIZ, Renato. A diversidade dos sotaques: o inglês e as ciências sociais. São Paulo: Brasiliense, 2008. 
CADERNOS CENPEC - E como se dão, nesse novo contexto, as relações entre cultura popular, cultura de prestígio e indústria cultural? Se possível, gostaríamos que você nos ajudasse a pensar algumas dessas relações no campo educacional. Tem-se percebido que há, no Brasil, uma presença cada vez maior da cultura popular nas escolas. Ao mesmo tempo, professores e alunos têm uma relação estreita com a cultura por alguns chamada de massa. A cultura "erudita" ou de prestígio, por sua vez, tem perdido espaço nas escolas, mesmo nos documentos curriculares oficiais. Esses elementos se tensionam dentro da escola?

RENATO ORTIZ - Sim, de certo modo. No entanto, creio que, hoje, o conceito de cultura de massas é difícil de ser utilizado. Ele surge num momento específico: nos Estados Unidos, nas décadas de 1930-1940, quando se fala da unidade de uma sociedade nacional em torno dos mesmos padrões. As indústrias culturais cumprem esse papel homogeneizador. Hoje, dificilmente se pensaria o mercado como um espaço homogêneo, existem segmentos de mercado. 0 processo de globalização acentua essa dimensão de segmentação. Por isso, o conceito de cultura de massa é mais difícil de ser usado. Por exemplo, a Al Jazeera é uma televisão global, mas ela não veicula uma “cultura de massa”. 0 mesmo pode ser dito da CNN. Trata-se de empresas televisivas que falam para segmentos específicos. Isso acontece também com o mundo do consumo, a distinção (no sentido de Bourdieu) se faz por meio deste mercado global.

A questão que vocês abordam é certamente complexa: como a escola deve lidar com a problemática cultural na contemporaneidade. É um problema que envolve múltiplas dimensões, e uma delas é a formação dos professores. Pelo que dizem os pesquisadores da área, há certo déficit de formação cultural. E aí temos um problema: devemos considerar a cultura popular como uma matriz que se sobrepõe ao saber escolar? Ou deve-se cultivar uma posição “elitista” que condena a cultura popular? Tenho a impressão de que é possível combinar as duas coisas. Primeiro, é necessário que os professores sejam formados dentro de padrões mais amplos, somente assim eles poderão ter uma perspectiva mais cosmopolita. Mas, por outro lado, eles podem trabalhar esses padrões junto ao universo de vida de seus estudantes; esta é uma maneira de estimulá-lo, pois a vivência e a experiência são elementos importantes para o aprendizado. 
CADERNOS CENPEC - No que se refere à realidade brasileira, que características ligadas à valorização da diversidade você destacaria em um país como o Brasil que tem, na sua história e construção de identidade, a representação de uma multiplicidade étnica, religiosa, racial e também cultural como um valor positivo? A relação com a diversidade ganha alguma peculiaridade?

RENATO ORTIZ - Sim, só que houve uma mudança nesse debate. Tratei desse assunto no texto que está no anexo do livro Universalismo e diversidade?. Como pensar a cultura brasileira e a identidade nacional dentro do contexto atual, globalizado. Um dos argumentos que levanto é que o tema da diversidade, clássico entre nós, vai numa direção, mas, na atualidade, ele se transforma. De maneira sintética, eu diria: nossa tradição pensava a diversidade como uma síntese - o mestiço é síntese de coisas diversas. No início, essa síntese nos conduzia a um impasse por causa das teorias racistas (particularmente no final do XIX e início do século XX). A partir da década de 1930, com o Estado Novo, a síntese se torna plausível, o mestiço seria a fusão harmônica dos traços de nossa identidade. Hoje, o tema da diversidade não é uma síntese, ele é mais analítico. Na verdade, ele separa as diferenças. 0 movimento negro reivindica cotas porque os negros foram sistematicamente discriminados ao longo da história brasileira (temos tendência em esquecer os traumas da escravidão). Mas para isso é necessário que eles explicitem uma diferença em relação aos outros. Isso não significa que não sejam brasileiros. São brasileiros, porém, afirmam o pertencimento à nação por meio desta diferencialidade.

CADERNOS CENPEC - A diversidade é afirmada como algo positivo agora.

RENATO ORTIZ - Sim. Essa positividade pode ser exercida por diferentes grupos sociais. Por exemplo, os indígenas. Eles enfatizam a diferença diante da síntese anterior que os apreendia como simples elementos simbólicos na composição de uma identidade nacional. Hoje é mais difícil dizer "o brasileiro" no singular. É isso que muda.

O título do anexo é Imagens do Brasil. 
CADERNOS CENPEC - No novo plano nacional de educação, aprovado em 2014, ganharam espaço questões relativas à diversidade e à cultura. No entanto, diferentemente do que ocorreu com os Parâmetros Curriculares Nacionais (PCN) no final da década de 1990 - que tratavam de questões como discriminação de gênero, diversidade sexual - hoje, quase 20 anos depois, puderam-se observar algumas fortes reações ao tratamento dessas questões. Um exemplo que a imprensa tem divulgado refere-se às reações de religiões evangélicas e católicas ao tratamento de questões ligadas às discussões sobre gênero (por eles chamadas de "ideologia de gênero"). Além desses grupos, alguns estados e municípios têm até proibido o tratamento dessas temáticas em seus documentos regionais. Você poderia nos ajudar a compreender o que mudou? O que isso nos diz sobre as relações entre o universal e o particular?

RENATO ORTIZ - O tema da diversidade é polissêmico. É esse o problema. Uma coisa é pensarmos a ideia de diversidade tal como ela é percebida pelos movimentos políticos, ou seja, nas reivindicações indígenas, negras, de gênero, etc. Nesse caso, determinados grupos, desfavorecidos socialmente, demandam certas políticas positivas. Políticas que se fundamentam em valores universais. Se eu sou negro e reivindico cotas na universidade, meu argumento é o seguinte: os negros foram discriminados pois a sociedade brasileira não conseguiu estender os direitos a todos os cidadãos.

Se eu fizesse a mesma reivindicação dizendo "sou negro e quero uma vaga", nada conseguiria. É necessário argumentar num sentido mais amplo. A mesma coisa vale para as mulheres. Elas não podem apenas dizer: "Somos mulheres e queremos determinados privilégios". Para nos convencer politicamente, elas afirmam: "Somos mulheres e na sociedade em que vivemos existe uma dominação masculina; os homens tiveram muito mais oportunidades do que nós, e o princípio de igualdade deveria valer para todos”. As ações positivas necessariamente incorporam argumentos universalizantes. Entretanto, o tema da diversidade tem duas caras. Por exemplo, o caso dos refugiados na Europa. Para muitos, esses imigrantes são vistos como uma ameaça à integração nacional e ao mercado de trabalho. Reivindica-se a "preservação da diversidade nacional" com base na exclusão daqueles que são estrangeiros. Estamos distantes dos ideais de igualdade ou de pluralismo. Por isso digo que a diversidade é um termo polissêmico. 
CADERNOS CENPEC - Outro tema polêmico na política educacional brasileira tem sido o debate sobre a criação da base nacional comum curricular (movimento presente em países como Estados Unidos, Austrália e Inglaterra e já consolidado na França). Uma das principais justificativas, entre os seus defensores, é a promoção de valores como justiça social, equidade e a garantia de uma educação comum a todos. No entanto, pesquisa realizada pelo Cenpec ${ }^{8}$ mostra que há uma forte oposição de alguns segmentos a essa proposta, especialmente no campo acadêmico. E, ainda, similarmente ao que ocorreu no debate sobre o Plano Nacional de Educação (PNE), há certa resistência (ou recusa), por alguns grupos, em tratar temáticas ligadas à questão da diversidade, bem como outras ligadas ao debate sobre a promoção da cidadania (por exemplo, projeto educacional brasileiro, educação como desenvolvimento integral, etc.). Como você analisaria tais tensões?

RENATO ORTIZ - Tenho a impressão de que aí existem alguns mal-entendidos. Primeiro, já existe muita coisa em comum: a língua, a história do país, a cultura televisiva, etc. Na verdade, não é a oposição entre o comum e o diverso que importa. A questão deveria ser: um padrão de ensino seria melhor para a educação? Creio que sim. 0 problema é que existe uma luta política em torno desse padrão. Como defini-lo?

CADERNOS CENPEC - Os EUA têm uma base curricular comum: os standards; a Austrália recentemente também elaborou um currículo comum.

RENATO ORTIZ - Observem como, nesta entrevista, o tema da diversidade vai mudando de figura. Uma coisa é falar de indígenas e negros, outra da diversidade em relação a um padrão curricular. Se considerarmos o mercado, teremos ainda outro nível de discussão. A pergunta que se deve fazer é: "O que há por trás do termo diversidade?”; ou ainda, "O que estamos dizendo com universalismo e diversidade?" Existe atualmente toda uma bibliografia crítica do universalismo, entretanto, não temos essa mesma distância crítica em relação ao tema da diversidade. Ela aparece como algo em bloco, um

\footnotetext{
A pesquisa Consensos e Dissensos sobre a Base Nacional Comum Curricular foi realizada entre 2013 e 2014, com o financiamento da Fundação Lemann. Seu objetivo foi conhecer as tomadas de posições de agentes (gestores públicos, professores universitários, professores da educação básica pública, membros de organizações da sociedade civil, sindicalistas e diretores de escolas privadas) atuantes na área de educação sobre a Base Nacional Comum e os processos de centralização e padronização curricular. Cf. Consensos e dissensos em torno de uma Base Nacional Comum Curricular no Brasil. Relatório de Pesquisa. Disponível em: 〈http://ftp.cenpec.org.br/com/portalcenpec/ biblioteca/Consensos_e_Dissensos_Relatorio_Pesquisa_Cenpec_Final.pdf.>. Acesso em: 15 nov. 2015.
} 
todo homogêneo. A ideia desse último livro é considerar de maneira crítica a polissemia desses termos. 0 que eles significam em diferentes contextos. Por isso digo, é distinto falarmos de currículo padrão, da questão indígena ou do racismo. 0 termo diversidade encobre, nesse caso, dimensões inteiramente diferentes.

\section{CADERNOS CENPEC - Em que sentido são distintos?}

RENATO ORTIZ - Veja, quando se discute se um país deveria ou não ter um padrão de ensino escolar, um argumento contrário poderia ser: "Isso não pode ser feito em função da diversidade”. Mas qual diversidade? Regional, religiosa, política. Seria ainda a desigualdade social uma diversidade?

A questão indígena nos remete a outro plano, trata-se de grupos sociais que foram oprimidos desde a colonização portuguesa até os dias de hoje. Os indígenas ocupam uma posição de subalternidade e, para reivindicar algum tipo de benefício, lançam mão do argumento da diversidade. 0 termo é o mesmo nos dois casos, mas os sentidos não são coincidentes. Eles recobrem níveis distintos. Por isso há no livro Universalismo e diversidade: contradições da modernidade-mundo um capítulo sobre diversidade de mercado ${ }^{9}$. 0 mesmo discurso é usado pelos agentes de mercado; quando querem vender os seus produtos em escala global, eles valorizam a diversidade. Se o mesmo argumento aparece em situações tão discrepantes, há um problema. O exercício que faço no livro é justamente compreender como o mesmo "conceito" (seria melhor dizer emblema) é utilizado em contextos tão discrepantes.

CADERNOS CENPEC - Mais uma questão que tem gerado polêmicas na esfera educacional refere-se à produção de material didático. No ensino de língua portuguesa, alguns linguistas têm defendido a presença da diversidade linguística do país que possa expressar, por exemplo, variantes sociais ou regionais como forma de atenuar a violência simbólica contida na norma escrita culta, ou, como se pode pensar, da língua considerada legítima. Algumas tentativas de dar espaço a essa "diversidade", trazendo frases e contextos mais ligados à linguagem oral regional/local (como um exemplo polêmico citado em um livro de Educação de Jovens e Adultos que tentaram tirar de circulação: "Nós pega os peixe", "Os menino feio"), têm gerado reações e críticas. Como você interpreta esse fenômeno?

9 Capítulo Diversidade e mercado. 
RENATO ORTIZ - Acho que é um excesso de zelo imaginar que a língua culta é a única língua real que falamos. A língua culta é uma língua específica e ela é importante e tem de ser trabalhada, mas a realidade linguística de um país não se resume a ela.

CADERNOS CENPEC - Sim, o livro também trazia a norma culta.

RENATO ORTIZ - Então não há problema. A língua culta não dá conta das variações dialetais, por isso, não vejo por que a escola não possa ensinar as variações dialetais, as diferenças e maneiras como essa língua se atualiza em regiões específicas ou até mesmo em grupos específicos. É até interessante e enriquecedor para o estudante perceber que não existe uma homogeneidade linguística tal como se supõe. Talvez muito da controvérsia atual no Brasil tenha a ver com o clima político, ou melhor, de sua polarização. Veja a questão de gênero, ela encontra-se vinculada a múltiplas dimensões, religiosa, sexual, o papel das mulheres numa sociedade dominada pelos homens, etc. Mas há ainda uma dimensão política, implícita ou explícita, que complica as coisas. É comum escutarmos a afirmação: "Gênero é coisa do PT [Partido dos Trabalhadores]". Assim, por analogia, se alguém é contra o PT, deveria se opor às políticas de "gênero". No caso da língua, tivemos um exemplo que beira o provincialismo atroz: deve-se utilizar o masculino ou 0 feminino para se nomear o(a) presidente do país? Cheguei a ler artigos na grande mídia dizendo que esse erro grotesco seria "culpa do PT". Bastaria ir ao dicionário para evitar esse tipo de tolice; na língua portuguesa existem as duas formas, presidente e presidenta. Mas voltando ao tema da língua culta, é muito bom que ela seja ensinada na escola, não apenas como um processo de "correção" da fala; a língua culta abre às pessoas todo um horizonte de expectativas novas: livros, teatro, cinema, artes. Seu ensino e aprendizado são fundamentais. Entretanto, isso não implica necessariamente o desconhecimento das variações de uma mesma língua. Como dizem os linguistas, somos capazes de falar uma língua e falar desta própria língua. Existe um elemento de reflexividade no aprendizado que nos permite falar do mundo e da língua que utilizamos para conhecê-lo.

CADERNOS CENPEC - Entre nossos principais interesses de pesquisa está a compreensão das várias facetas da produção e enfrentamento das desigualdades educacionais. Que elementos você considera importantes a ser destacados na relação entre diversidade e desigualdade?

RENATO ORTIZ - É importante distinguir entre diversidade e desigualdade. A questão da diversidade nos remete às diferenças, a da desigualdade às 
posições hierárquicas que os indivíduos ocupam na sociedade. Temos às vezes tendência a reificar a "diversidade", sobretudo quando discutimos sobre as identidades. Falamos da identidade nacional como se ela fosse uma essência, às vezes, da própria identidade negra ou indígena. Como se cada uma delas fosse uma diferença fechada sobre si mesma. As diferenças são sempre relacionais, elas pressupõem um contexto e diversos atores atuando nesse contexto. Por exemplo: o racismo fundamenta-se na ideia da diversidade racial. Ele ordena as raças superiores numa posição de superioridade às inferiores. Mas seria isso sinônimo de pluralismo? É o que dizem os movimentos de direita na Europa. "Não queremos esses islâmicos, eles fazem parte de outra raça." Já não é mais necessário dizer que alguns são superiores e outros inferiores. 0 argumento muda e invoca a positividade da "diversidade": "Somos de outra identidade e não queremos misturá-la com a deles".

CADERNOS CENPEC - E, nessa linha, como você explica a questão da identidade?

RENATO ORTIZ - Existe uma substantivação indevida da identidade - como se ela existisse em si. É preciso pensar a temática da diversidade de maneira crítica, ou seja, qualificá-la. A amplitude do termo termina por ocultar uma série de questões. Meu esforço foi no sentido de pegar a caixinha da diversidade e abrir, abrir, até obter os vários sentidos que o termo adquire.

CADERNOS CENPEC - E quanto à questão de trazer o diverso para o universal? Por exemplo, será que todos os brasileiros têm de aprender um pouco sobre as culturas indígenas e suas diferenças? Isso aparece menos ainda, não?

RENATO ORTIZ - Eu diria que depende do “diverso" e do "universal” de que se está falando. Para um brasileiro é importante entender um pouco das culturas indígenas que compõem o país. Mais importante ainda, corrigir o viés da narrativa histórica que predominava ou ainda predomina entre nós. Mas a questão é mais ampla do que isso. Dou um exemplo pessoal. Em meados dos anos 2000, a Unesco convidou-me para fazer parte de um grupo de intelectuais e discutir a temática do universal e da diversidade. Eles tinham um problema prático: como classificar as obras “universais excepcionais”. Havia dezenas de pedidos nessa direção, classificação de cidades, monumentos, sítios ecológicos, etc. Ingenuamente pensavam que este pequeno grupo iluminaria suas dúvidas e impasses. Permanecemos três dias reunidos, claro, sem chegar a nenhuma conclusão. Achei aquilo fantástico. Havia um equívoco preliminar: se uma obra era excepcional, não poderia ser universal. Afinal, o 
excepcional era o diferente. Mas foi justamente essa aparente contradição que me chamou a atenção. Ela me remetia à ideia de oximoro. Um oximoro é uma figura de linguagem composta de dois termos contrários (por exemplo: silêncio ensurdecedor). No entanto, esses termos, ao se negarem entre si, afirmam algo de verdadeiro. Eu diria que a diversidade como valor universal é um oximoro (a tensão entre universal e diverso permanece). Oximoro que fala do mundo contemporâneo. Foi essa a ideia inicial do livro.

CADERNOS CENPEC - Assim, no seu entender, o debate não é contra a diversidade, ele se dá em outra base; a diversidade seria um dos temas, por exemplo, a ser tratado na sua especificidade.

RENATO ORTIZ - Exatamente. Aquilo que num primeiro momento aparece como homogêneo ou heterogêneo, antagônico ou dicotômico, na verdade está unido. Há pessoas que acham que estaríamos vivendo o fim do universal, a presença excessiva da diversidade levaria o mundo ao caos. É o contrário! Porque o mundo é comum é que o diverso tornou-se importante.

CADERNOS CENPEC - E a diversidade ganha um valor positivado.

RENATO ORTIZ - Sim! E isso é um acontecimento recente na história dos homens. O tema da "diversidade" não existia, da forma como o compreendemos hoje, no passado. Na Antiguidade helênica os gregos se contrapunham aos bárbaros; no Império Romano havia os romanos e os outros; no império celestial da China existiam os chineses e os estrangeiros. Era assim que funcionava 0 mundo. Nos anos 1960, os Estados Unidos invadiram o Vietnã. A população do Vietnã não diria: “Em nome da diversidade do povo vietnamita, somos contra os americanos". O problema era outro, tratava-se de uma invasão imperialista no âmbito da guerra fria. $O$ contexto era outro. Entender o oximoro é entender as mudanças do contexto histórico. Nele as relações entre universalismo e diversidade devem ser compreendidas.

CADERNOS CENPEC - E desse modo só é possível afirmar a possibilidade do universal porque existe um contexto que o afirma com muita força?

RENATO ORTIZ - Exatamente. Por isso escrevi um capítulo sobre o relativismo cultural. Não sei se vai interessar a algum leitor, além dos antropólogos. Mas a escola culturalista norte-americana de 1900 a 1950 trabalhou especificamente a temática da diversidade cultural. Eu queria fazer um trabalho arqueológico e recuperar alguns dos argumentos elaborados e ver como eles reverberavam ainda no presente. Só que o argumento central dos culturalistas americanos é que a cultura é uma coisa singular que se fecha sobre si mesma. Por isso 
os antropólogos eram, no passado, não atualmente, contrários à ideia de direitos humanos. Cada cultura teria uma concepção específica do que seria o direito, não seria possível falarmos de um direito de vocação universal. 0 que nos leva certamente a vários impasses.

CADERNOS CENPEC - Porque o mundo chamado ocidental é hegemônico, outros foram classificados de primitivos, não é mesmo?

RENATO ORTIZ - Isso mesmo. Mas atualmente os povos indígenas, mesmo os que vivem no interior da Amazônia, pouco têm de "primitivos". Eles têm avião, helicóptero, computador, uma série de coisas. Isso mostra a comunalidade da modernidade. Ninguém escapa do mundo globalizado. Porque não escapamos, temos de ser diferentes.

CADERNOS CENPEC - Essa é uma boa frase, que resume a temática desta entrevista, não?

RENATO ORTIZ - Exato. Mas existe um hiato entre a realidade que se forma e a consciência que dela possuímos. Veja um exemplo: a crise econômica atual é de natureza mundial, entretanto, parece não termos clareza disso. Na província Brasil, tudo se passa como se os problemas fossem unicamente locais. Imagina-se, ideologicamente, a existência de um país isolado do mundo. O nacional nos obceca a tal ponto que esquecemos aquilo que nos envolve e determina boa parte do nosso destino. 